\title{
The Impact Technology Has Had on High School Education over the Years
}

\author{
Egemen Hanımoğlu ${ }^{1, *}$ \\ ${ }^{1}$ Faculty of Education, Cukurova University, Adana, Turkey \\ *Correspondence: Faculty of Education, Cukurova University, Adana, Turkey. Tel: 90-507-208-3108. E-mail: \\ ehanimoglu@gmail.com
}

Received: November 14, 2018

Accepted: December 7, 2018 Online Published: December 17, 2018

doi:10.5430/wje.v8n6p96

URL: https://doi.org/10.5430/wje.v8n6p96

\begin{abstract}
Technology in secondary school is of great importance to students and teachers. School management teams focus on ensuring that learners have access to computers during the high school years. The existence of the internet has led to an increase in the drive to promote the availability of computers to all high school scholars. For instance, wiring the institutions and classrooms is a measure adopted to improve access to quality education facilitated by internet use. Through technology, various concepts related to learning can be shared easily. Integration of IT in learning process requires practical skills and access to technological tools for teachers. Therefore, many academic institutions have significantly invested in the purchase of equipment. The current study analyses various literature focusing on the roles that technology has played on high school education over the years. The critical area to focus on includes technology and interaction of teachers, students, benefits of the technology, as well as possible drawbacks. Accordingly, integrating online learning and teaching activities plays a crucial role in accommodating student's diverse learning styles. In addition, such strategies can assist leaner's to work before or after school, unlike in conditions where only classroom learning occurs.
\end{abstract}

Keywords: technology, education, school, impact, high school

\section{Introduction}

Reforms in schools have focused on promoting interaction of teachers and learners and enhancing the level of teaching in the contemporary era. New inventions led to the establishment of advanced gadgets such as computers and cell phones that increase communication and interactions (Asterhan \& Rosenberg, 2015). High schools have also benefitted from innovation particularly in the communication industry. Institutions of learning work to guarantee that the schools respond to technological transformations in the ratio of learners to computers. Since the late 20th century mainly in the 1980s, acquisition of machines has been the primary focus of high school institutions to promote technological access. Improvement in the number of students to computers abridged from 72 in 1983 to below 6 in 1999 for every learner (Cuban et al., 2001). School management teams have always focused on ensuring that learners have access to computers during the high school years. The existence of the internet has led to an increased drive to promote the availability of computers to all high school scholars. For instance, wiring the institutions and classrooms are a measure implemented to advance access to quality education facilitated by the internet use. According to the study by Cuban, Kirkpatrick, and Peck, 35 percent of schools had been connected to the internet and by 1999 wiring of buildings increased to 90 percent while the internet connection to classrooms was 3 percent (Cuban et al., 2001).

Accessibility to computers has also been facilitated by the introduction of computer labs in many high schools. Students have the lessons conducted in the laboratory to enable them to use the computers in learning. Besides, teachers and learners have access to computers in their homes so that they can easily network with the modern technology. There are also media centers with adequate machines that can accommodate the classroom during selected lessons. Provision of computers is considered a significant approach of promoting technology in high school (Simon \& Ngololo, 2015). Several quantitative studies conducted from 1995 involving the effect of technology on teacher-learner perception, acquisition of various ability, and utilization of technological tools indicates that high achievement in secondary schools has been attained (Knezek \& Christensen, 2002). Early exposure to computers in high school leads to participation by students in class activities and learners being delightful. Besides, gender 
differences are eradicated as learners interact freely in computer rooms as well as with teachers. Increased teacher competence and confidence in information technology ensures classrooms are managed effectively (Islam \& Grönlund, 2016). Integration of technology in the classroom effectively requires improved skills and access to technological tools for teachers. As a result, schools are encouraged to adopt computer in their teaching.

Utilization of technology in high schools has facilitated global cooperation about integrating ICT in learning. The exchange of thoughts is highly appreciated mainly for research on the efficacy of ICT for teachers (Yilmaz, 2017). In high school, learners benefit more as a result of the introduction of different gadgets within their learning. Technology is essential to both teachers and learner as it eases and promotes better understanding. Use of smart boards is an excellent innovation in high schools and can be used for a range of purposes including lesson planning.

\subsection{Background of the Study}

High school instructors experience difficulties when preparing learners for future careers and studies such as colleges. Technology is intended to improve achievements in various fields and improve the capability of students to make well-versed decisions in the future. In the past, most specialists in technology have reported a shortage in computer access in several schools (Heitink et al., 2016). Application of new inventions such as computers in schools mostly involves essential functions such as the use of projectors when teaching, sharing maps, and notes (Huizenga et al., 2017). Students in most instances use computers for word processing and taking notes. Therefore, since there is no adequate use of technology, there is a need to research its application in high school over the years. Apart from the research, students can apply technology for other functions like improving their skills for future careers and critical thinking. Learners can create new information, which can lead to increased innovations. Other uses include doing online quizzes, online databases and classes, and other works such as blogging. Videos can be used for class work and homework, which enhances classroom activities enabling interaction between the learners and their teachers. Mobile devices have become more familiar to learners and analyzing the benefits is of great importance (Chang et al., 2018). Several countries are currently supporting online learning, which helps to supplement classroom work. Learners need to know ways of utilizing the modern inventions for classroom together with other activities such as training manuals on co-curricular activities, which can assist in discovering talents.

\subsection{Literature Review}

Several types of research have evaluated and analyzed the efficacy of using modern technology in high schools. Such investigations reveal that application of computers, internet, and other gadgets has affected learning, student-teacher interaction, student-student interaction, and quality of education among others. Some studies have also had some negative impact as revealed by some of the research findings. Hence, there is a need for blended learning opportunities to offer students a chance to explore their capabilities. Blending online learning and teaching activities play a role in accommodating learners' diverse learning styles. In addition, such strategies can help students to work before or after school, unlike situations where only classroom learning occurs. Researching ways in which the technology can improve productivity in schools by hastening the level of training need to be investigated. The study focuses on determining how technology is used in schools, and the benefits realized over time.

\subsubsection{Technology in Education}

Wenglinsky studied the relationship between different applications of education and its outcomes. The research involved the collection of statistics from the National Assessment of Education advancement in mathematics. The sample consisted of 6,227 learners in the fourth grade and 7,146 from eighth grade. The information sought was related to the frequency of computer use in studying mathematics in school set up, the availability of computers at homes, the use of computers by teachers as well as technology to give instructions. According to the findings, there are inequities in the manner in which computer are used. Schools in poor urban and rural areas may lack opportunities to develop computers effusively (Wenglinsky, 1998). Therefore, teachers from regions that have not embraced the utilization of information technology have less technical skills compared to those in developed urban centers. The study concluded that computers are not the solution to all problems schools might be experiencing, although they present a comprehensive tool for proficiency in mathematics.

In the study by Clotfelter et al. (2010), they employed statewide end-of-course tests that were carried out in Carolina to establish the connection among tutors qualifications and learners achievement in high schools. According to the findings, there was compelling proof that tutors qualifications, especially the license and credited ones, have significant impacts on learner success of high magnitude. The results mean that the uneven division of tutor testimonial brought about by racial profiling and economic condition of school learners influenced student achievement (Clotfelter et al., 2010). Teachers with certified computer education performed better in ensuring 
learners utilize modern technology in attaining their goals of being successful in learning (Van den Beemt \& Diepstraten, 2016).

The existence of technologies in the class set up learning has been effective particularly in ensuring the improvement of in-service teacher education and preparation for pre-service instructors to make sure successful alignment of educational technology in the learning activities. Recently teacher-learning establishment is making an effort to prepare for pre-service tutors to make sure there is an integration of technology into the future teaching practices mainly in high school (Anderson, 2016). Some strategies include the introduction of technology to pre-service teaching professionals, delivering of technology courses, giving mini-workshops, integration of technology in all learning units, and modeling on the usage of technology among others. For instance, in countries such as China, the government pays considerable attention to the preparation of learners-tutors to align ICT in the future learning practices, by giving ICT educational coursework. Incorporation of computer systems into the learning system has become a primary objective of many countries since it improves performance after the student attends post-secondary levels (Borokhovski et al., 2016). However, unless there is interlink between tutors and computers is implemented, it might be challenging to attain the principal targets. By understanding the method of achieving incorporation, there is a need to study more on teacher training for high school institutions. Instructors that obtain proper learning in the field of ICT may vary in coming days mainly in the utilization of computers for tutoring from tutors that might not have got a better education.

\subsubsection{Technology and Student Collaboration and Motivation}

Goldin and Katz (2018) researched on three factors that increase students' motivation in the technologically enhanced setting. The factors included communication, learning, and empowerment as students appreciated how they interact with others in real time by using technologies such as computers. Connecting with others is made possible by the internet enabling real-time communication. The learners were empowered in a technology surrounding, as they were secluded from teachers and were less scared of relating to others. Learners believed that computer enables them to have control over their learning by promoting independence (Goldin \& Katz, 2018).

Previous research has also shown that attitudes towards ICT do not significantly depend on gender. Teachers' attitudes toward ICT are multifaceted although with continued training positive results can be achieved (Ibieta et al., 2017). Anxiety decreases very quickly due to constant exposure to technology. However, the evolution of ICT is quite slow regarding productivity and can be prolonged. Usefulness of applying ICT in high schools is of great importance in different countries. Various nations have different connectivity and access to ICT resources and the current state of technological advancement. Complete integration of technology in the classrooms helps in improving the cognitive functions and meeting the needs of high school learners.

Introduction of modern technology in high schools has also had a significant impact on teaching by a generalization of teachers' schedules (Ibieta et al., 2017). For instance, lesson preparation has been supported by emerging inventions, especially computers. Teachers can plan interactive and creative lessons as well as set assignments using various technologies in a class setting. Instructors can use technology for assessing learners in various forms although overall technology is capable of enhancing tests through the provision of flexible designs. Learners' skills and competencies can be established, and teachers can utilize real-time feedback. Therefore, technology enhances student-teacher interactions improving understanding of the critical content. The tutor can explain concepts severally for students to comprehend what is being taught. The adoption of technology in this area leads to overall improvement in reporting and student grades (Abboud \& Rogalski, 2017). The use of technology in high school can help break down boundaries, as it does not limit the lesson period. Therefore, there is the creation of an authentic learning continuum between home and school due to empowerment in the latter. Students and their instructors can take more control in the learning process and harness the capabilities of gaining new experiences thus encouraging quality studies outside libraries and classroom (Kennewell et al., 2008). Learners can utilize technology to facilitate the meeting, collaborating, and creating content virtually. Collaboration is also possible through technology due to the flexibility that helps students to work in an environment considered as more collaborative. Technology is vital for mutual learning enabling interaction between teachers and learners. Students can always contribute to lesson content and engage with their colleagues in solving problems during lesson time. Use of mobile devices and laptops is the best for remote and online learning. Students are continually generating new approaches to problem-solving as well as learning ways of working alongside their peers. Future careers of high school students are enhanced when technology is used to support teaching. Textbooks are still crucial in the classroom for references and extensive research. However, students use laptops and tablet while others use Smartphone for classroom-related work. Homework and assignments can be downloaded easily by learners and be submitted to the tutors via email or other 
platforms.

Technological advancements have led to significant changes in education, especially the utilization of the internet. Sharma and colleagues did research analyzing the web-based learning and its effect on the motivation of students by the internet. Use of documentaries together with movies helps learners to understand classroom content better. Flexibility ensures collaborative learning in a classroom environment. The study findings encourage researchers willing to actualize the notion of technology used during lessons (Sharma et al., 2009). Recently, the evolution of portable gadgets, wireless devices, and network inventions has been highly developed. The incorporation is expected to use technologies in a high school environment for teachers together with learners in using modern innovations (Singh, 2018). Mobile devices facilitate the connection between tutors and learners to use computing capabilities anywhere. The internet and wireless technology promote interlink amidst mobile gadgets with other computing devices such as computers, tablets, and other items (Hinostroza et al., 2016). Recently empirical research has revealed the benefits of using wireless technology and portable gadgets in high school learning surrounding to enhance accessibility and convenience of information interconnection (Shernoff et al., 2017). Helping students to participate in learning-related activities regardless of where they are, offering support to groups working on a plan, and improving communication and joint education in the classroom is essential.

\subsubsection{Teach-Student Interactions and Technology Use}

Muir-Herzig (2004) researched to determine the impact of the extent of using computers in the class setting on learners' performance and turnout. He used the tutor technology survey in measuring teachers, students, and overall use of technology inside classrooms. The study utilized a sample that comprises of tutors from the Northwest Ohio high school (Muir-Herzig, 2004). The findings of the research indicated that instructors, learners and general use of technology do not significantly offer positive impacts on the attendance and academic performance of the at-risk learners.

Furthermore, from the research, it was evident that the application of technology was minimal amongst the tutors in the sampled population. From the results, it was clear that technologies to have positive effects and make a change in at-risk learners' attendance and academic performance, high school, and other institutions must be prepared to apply modern inventions in the classroom. The administrators of such institutions must develop a model that should include a shared ideology, in the entire system and ensure community involvement. Facebook is an effective mean of communication for learners and tutors to exchange knowledge and record greater achievements (Aaen et al., 2016). In addition, specific training for employees and allocating enough time for technology adoption in the schools can enhance the value of education. The impacts of technology use in the institutions of learning mainly in secondary level result in positive changes among students and the teachers. Technology is considered a significant tool for positive change although there is a need for it to be used effectively.

According to Stepp-Greany, Substantial learning occurs through learners' interaction with peers and ensuring the context is aligned to their needs. In this case, constructing a resourceful and interaction-rich learning environment in high schools is essential in facilitating learners' studies. Resources located in conventional classrooms at times restrict students to make inquiries, ascertain, examine and unravel emerging issues (Stepp-Greany, 2002). Furthermore, computer classes, with fixed PCs and network infrastructure are likely to prevent students from utilizing their technical skills effectively. Mobile learning gadgets can resolve the impasse in conventional and computer classrooms allowing learners to engage in both physical and implicit learning actions

Sang et al. studied learners-tutors' reasoning capacity and ICT alignment. According to this research, learners and tutors should prepare to integrate ICT into the educational practices and future learning. The research also found that although there is better accessibility concerning ICT incorporation, few instructors are ready to align ICT with their tutoring actions. The study largely focused on different tutor interlinked variables in explaining the low level of integrating ICT into the high school curriculum. In addition, results showed that potential ICT incorporation has a significant correlation with instructor related variables, except the gender (Sang et al., 2010). Therefore, prospective ICT integration may be directly anticipated based on tutor perception and factors like teacher's self-efficacy, constructivist tutoring beliefs, and computer effectiveness and learners attitude in education. Nevertheless, the gender of the learner or teacher influences integration.

Goos and colleagues in their study examined information from the three-year research of secondary school class set up in determining the pedagogical issues in the utilization of technological resources. The area of interest was mathematics teaching mainly graphics and overhead projections that enable screen display to be observed by the entire class. The researchers identified four functions of technology related to teaching and learning interactions. The four include master, servant, associate, as well as improving self-using information from five senior high school 
mathematics classrooms to show the role of technology in facilitating mutual inquest during group and class discussion. In technology as a master function, the instructors are deferential and can only apply the features limited by individual skills or circumstance. Technology as a servant indicates that the user has knowledge of technology but applies it just in restricted ways in maintaining of the ideal learning process. Therefore, technology is not used resourcefully to transform the critical nature of various actions. For instance, a projector is used to provide means for teachers to display outcome in the classroom. Technology as a cohort involves the situation in which instructors have grown an affinity for a class where there is the provision of teaching resources (Goos, 2000). In this case, the technique is applied innovatively to raise the learners' power in their learning. The instructor does not exercise authority over the students to ensure enhancement of individual prowess, sharing, testing, and reworking of some concepts. Technology is fundamental for a teacher to perform functions involving mathematical and scientific skills.

Cavas, Karaoglan, and Kisla argue that combining ICT in training is a vital matter in several nations. In the recent times, the Turkish Ministry of Education has demonstrated an interest in investing in the ICT and ensured learners acquire the requisite skills they need. Conversely, ICT tools are given to instructors without consideration of their attitudes towards modern inventions. The study aimed at revealing the perspective of Turkish science instructors' towards integrating ICT in teaching and then exploring the connection amidst tutors attitude and various aspects interlinked to their attributes such as sexual characteristics, age, computer ownership at home, and having requisite skills (Cavas et al., 2009). The findings illustrate that Turkish science tutors demonstrated a positive attitude toward ICT, but there is no connection with gender. However, age, individuals owning computers, and having the required skills influence teachers using computer technology in school.

The integrating of ICT into the education system in high school is considered the perspective of the new innovational methods that are intended to transfigure the educational approach. Research on the initiatives, projects, and impacts of using information and communication technologies into education are motivating factors for tutors to acquire necessary knowledge and skills in applying ICT during instruction. Cavas, Karaoglan, and Kisla in their study note that ICT is the basis of the information period, and is considered a vital catalyst and tool for induction of educational reforms, which bring changes to students transforming them to industrious and knowledgeable workers (Canvas et al., 2009). ICT is critical in ensuring the growth of information within the societies and a response to the students' current needs. In such condition, the significant shareholders of education need to reform and re-enact the educational approaches to incorporate new teaching methodology, which include a constructivist approach to make sure that instructors together with students get the necessary knowledge as well as the skills needed in the digital age (De Vita et al., 2018). Therefore, many nations globally focus on ways for integrating ICT in teaching to make sure there is an improvement of the eminence of academic by emphasizing various skills like critical thoughts, decision-making, and handling of changing conditions, teamwork, and effective communicating among others. In addition, governments such as those in developing nations try improving their national programs, for instance, integrating of ICT in the system of education (Manca \& Ranieri, 2017). However, in some cases, government programs are not successful in their implementation of ICT into various teaching programs, since the formulation is mostly done in non-educational realms. Sometimes there is little support for educational research. Involving ICT in Turkish education systems is likely to improve performance in high schools especially enhancement of teacher relations with learners. The first trial of introducing computers was done in 1984 in the Turkish school systems through initiating a Computer-Aided Education (CAE) Project (Cavas et al., 2009). The Ministry of National Education (MoNE) was aiming at widening the awareness of computer skills as well as application amidst tutors to help in improving the level of teaching surrounding. The MoNE sees the utilization of new technology in teaching as quite important and as a result funded several projects that support the usage of ICT in education.

\subsubsection{Student-Student Interactions}

Picciano argues that interaction is significant for the success of learners in different courses. The perception of students in quality and quantity of their interactions with colleagues and technology is of great importance (Picciano, 2002). Penning et al. (2014) studied the teacher-learner connection developed from real-time tutor-student interlinks (Penning et al., 2014). Such links are facilitated by interpersonal contents, arrangement, and complementary in a group set up. A computer joystick device was used for measuring tutor and leaner's interpersonal behaviors as a two perspective methodology that blended agency and communion (Anderson, 2016). The outcome demonstrated that critical contents and complementarily discriminates amidst instructors while interpersonal structures did not. Measurements of such characteristics seem to help in understanding differences in teacher-student relationships.

In another study, Beauvois found out that learners who participated in projects of Local Area network writing had a constructive attitude towards learning in such a setting. LAN could provide a low-anxiety situation enabling the 
learners to work freely and discover more about their abilities. In the traditional classroom system of learning the teachers were controlling everything and learners had no room for self-discoveries (Beauvois, 1998). Modern technology is vital in enhancing the independence of students and ensuring that they can work on their own and innovate more. The study focused on the Internet-based technology linking it to quality learning in high schools.

Smith et al. found out in their study that technology increased bullying in high school. According to the research, the general harassment was $14.1 \%$ classified as often in, which it occurred twice, or thrice a month weekly. The study also found that $31.5 \%$ experienced cyber-bullying only once or twice a month while $54.3 \%$ were never bullied (Smith et al., 2008). The findings by Cavas, Karaoglan and Kisla on instructor capability of handling the technology revealed that half of the science instructors enrolled for in-service retraining related to ICT, 84 percent were very willing to participate in case another ICT training course was organized. The same study revealed that $63 \%$ of the instructors said that their schools had IT laboratories while $48 \%$ of them used computers to teach. Half of the tutors researched expressed confidence in utilizing programs like Word, PowerPoint, and Excel. However, only about 20\% were competent in using graphics programs such as Paint, Photoshop, and Corel draw among others. The percentage of the teachers that accessed the internet in their places of residence was $52 \%$ and in academic institutions $53 \%$ while those tutors owning e-mail address were $61.8 \%$; on the other hand, $8 \%$ had website pages (Cavas et al., 2009)

Use of class WhatsApp groups was found to be the main channel of conveying information for school-related topics according to a study by Rosenberg and Asterhan (2018). The app is used for organizing work such as sending and receiving updates together with managing learning activities. The study also indicated that teachers used WhatsApp for enforcing discipline. Some of the limitations identified include communication overload and the inability of teachers to monitor student interactions in social media during class time (Rosenberg \& Asterhan, 2018). Penning et al. indicated that WhatsApp-based, teacher-student groups have several educational purposes that include organizational, instructional, educational, and disciplinary (Penning et al., 2014). Tutors and learners recognize WhatsApp as one of the most preferred channels of conveying information due to minimal disclosure to private information and incursion of an individual privacy

Rueda, Benitez, and Braojos theorized that established teaching technologies allow teachers to engage learners and improve on teaching goals leading to higher student satisfaction. The social media applications are capable of strengthening such relationships (Rueda et al., 2017). Shute and Rahimi found that the use of computer-based assessment for learning through the internet or embedding it in a game yields positive outcomes in several subjects, for example, biology, mathematics, and encoding among others. The study concluded that in addition to efficiency, reliability and validity feedback is also of essential benefit to the learning process (Shute \& Rahimi, 2017). Technology has created a way towards new techniques of assessment that will help in supporting education by accurately measuring and supporting competencies that are complex.

Hegedus and colleagues researched improved algebra classrooms in the United States of America, evaluating the impacts of replacement of algebra prospectus with a set of integrated interactive software and they found out that the technology of wireless interconnection improved the prosperity of learner's education (Hegedus, 2015). The research investigated the efficacy of using Interactive Whiteboard (IWB) in a school set up program adopting a quasi-experimental design. The participants were divided into the IWB and general ICT-integrated learning atmosphere. A pre-test of the cumulative evaluation was given, and afterward, learners did a summative assessment test (Yang et al., 2015). The results showed that learners who were the members of the IWB group revealed greater effectiveness and developed a positive attitude towards learning. The verbal interaction in the IWB groups involved little lecturing and increased active participation by learners.

\subsubsection{The Negative Impact of Using Technology in Secondary Schools}

Smith et al. study found that technology in high school could have an adverse effect such as cyberbullying. The findings indicate that such crimes are less frequent compared to the traditional bullying (Smith et al., 2008). However, many cases have been reported within the schools compared to other places. Misuse of school technological gadgets is linked to the existence of cases of cyber-bullying of colleagues. Bingimlas in his work claimed that teachers were willing to integrate technology in teaching but faced many obstacles. Some of the barriers encountered include the lack of confidence, inadequate competences, scarce resources, and time (Bingimlas, 2009). ICT resources include hardware, software, technical support, and professional development, which need to be availed to teachers. Incorporating all the components can make it easier for high school teachers to integrate technology in schools and achieve active learning in the school environment (Zheng \& Warschauer, 2015). Lack of confidence hinders utilization of modern technology in the learning process, and the leading cause of lacking confidence is fear of failure and anxiety concerning usage of new methods during classes. Instructors fear attending 
classrooms with inadequate resources since some learners have more computer skills compared to them. Lack of competence by tutors also hinders the incorporation of ICT during class time in pedagogical practice (Brown, 2015). However, this barrier differs from one country to the other since in other nations especially the developing ones; the level of incompetence in technology is quite high. Resistance to change is one of the significant problems that are to be solved to make sure that a comprehensive combination of the computer technology in secondary schools. Teachers' attitudes limit the extent of technology use since most tutors are not willing to change their old ways (Darling-Aduana \& Heinrich, 2017). Some issues are caused by school levels such as the lack of adequate time allocation for incorporating new technologies. The limitation is quite common, as it requires the use of extra time for students to work with technological gadgets. Also, inadequate training of teachers has become a significant barrier. The recent study in Turkey pointed out that the primary issue with the adoption of information technology in science in schools is the lack of adequate in-service training for teachers. Without knowledge on ways of using contemporary inventions, it is unfeasible to apply them in high schools and other educational institutions.

\section{Methodology}

The study utilized a systematic literature review of previous research evaluating how the integration of ICT in the learning process impact on various aspects such as student-teacher interaction. The search was extensive, explicit and targeted multiple articles printed and reviewed within a particular timeframe from 1980-2017. Title, abstract, introduction systematically examined full text of studies considered eligible for use, and objectives to help in determining whether they met the inclusion criteria outlined. The search topics included how technology has affected student-teacher interactions and student-student interactions. Has technology been good or bad for general academic performance? Has it helped teachers deliver their content better? Does it interfere with the integrity of student work? Does it disrupt or does it aid students to focus on their work? The search strategy involves identifying keywords and statements interlinked to the most study question. The keywords and phrases will be searched using journal titles, article titles, names of authors as well as abstract with information related to the topic of study.

The search strategy generated 300 publications from electronic databases such as Google Scholar, JSTOR, and World Cat. Out of the studies, 100 were eliminated due to duplication. Articles on the impact of incorporating ICT into the learning program and "The Turkish Online Journal of Educational Technology" were searched. After screening all the source titles and abstracts of the remaining 200 publications, 46 were considered eligible and incorporated in the research. An average of 17 studies was excluded for failing to meet inclusion criteria or was not written in English. The sample size of the articles selected was sufficient as they contain content relevant to the topic. Some reports included information pertinent to the problem of study but the language used was unfamiliar to the researcher leading to exclusion. In this study, articles selected were supposed to be in the English language to meet the selection criteria. The importance of using systematic review is to ensure the promotion of using quality studies practice to support the arguments in technology innovation in secondary schools. Literature reviews are used to introduce the topics and summarize the discussed topic. The materials reviewed showed the evidence of quality research by recording the manner in which the primary studies are conducted. The literature reviewed should demonstrate the way they were analyzed as well as how the conclusion was done. Systematic review enables the authors to have more significant insights into the concepts being addressed in every work.

\subsection{Research Design}

The study uses a systematic evaluation of literature design to establish the impact of technology in high school settings. The model will involve critically appraising research and synthesize studies to provide a comprehensive, exhaustive summary of the evidence relevant to the research question.

\subsection{Challenges}

Carrying out research using systematic literature review poses some challenges that include researching of many sources and selection of only the important ones. The activity consumes much time, as the researcher must focus on establishing if the source contains the facts considered relevant in supporting arguments and providing evidence (Ginieis et al., 2012). The challenges can be addressed by narrowing down the search and using particular questions and search words. Applying the exclusion criteria facilitates selection that is necessary for the research and discarding the irrelevant ones.

\subsubsection{Advantages of Using Systematic Literature}

Methodical literature analysis was the most suitable for this study since it has advantages such as the capability to evaluate many studies that provide consistent results. Furthermore, the method increases objectivity hence reducing 
the implicit researcher bias by encouraging the researcher to critically analyze and evaluation of academic resources (Mulrow, 1994). Such action ensures high reliability of the study increasing its credibility. The method also facilitates explicability as the person studying a particular phenomenon obtains several sources related to the subject being studied, which improves the reliability of the findings.

\subsubsection{Limitations and Risks of Using the Design and Solution}

The design used consumes much time since it involves selection of only a few sources from several scholarly types of research generated after a search of the topic of study. One risk in this kind of research is the difficulties encountered when combining sources, in which a researcher has to narrow down to a particular area (Mulrow, 1994). The issue can be countered by choosing only information addressing the research question for analysis and focusing on the topic of study.

\subsection{Data Analysis and Findings}

In 2008, Smith (2008) found out that, bullying was one of the adverse effects of technology in high schools and science teachers were willing to attend training in ICT. The general harassment was $14.1 \%$ occurring two or three times a month, in which $31.5 \%$ were cyber-bullied only once or twice a month while $54.3 \%$ did not experience. Fifty percent of tutors used Word, PowerPoint and Excel but only 20\% showed competence in using graphics software such as Paint, Photoshop, and Corel draw among others. The percentage of teachers that used computers in their home is $52 \%$ while from schools was $53 \%$. In addition, those tutors owning e-mail address were $61.8 \%$; on the other hand, $8 \%$ had website pages. Another significant finding was that WhatsApp was the primary method of conveying information for a school-related subject for functions such as sending and receiving updates as well as managing learning activities. Teachers used WhatsApp for enforcing discipline to learners although there was a problem of monitoring learners' activities outside the classroom as well as communication overload. Teaching technologies were found to engage students and enhance teaching performance leading to higher level of learner's contentment especially the use of social media networks. In addition, use of computer - based assessment enhanced learning in several areas such as biology, mathematics, and programming among others. Technology has facilitated new assessment techniques that support education and accurately measure complex competencies. Use of curriculum that integrated lively interactive software, wireless linkages, and technology improved learners experience in the classroom. There was also an improvement in the vital algebra model such as practical and theoretical problems. Use of students' Whiteboard (IWB) produced significantly better learning experiences and increase positive attitude towards learning.

Similarly, the use of IWB encourages verbal interaction and little lecturing leading to more and improved participation by learners. According to Beauvois (1998), the integration of technology in learning helps the students to become independent and also encourages innovation. Shute and Rahimi (2017) found out that the adoption of technology in the education sector fosters efficiency, reliability, and validity of education.

\section{Conclusion}

The study found out that using technology in schools has several benefits to students and teachers. A computer is a vital tool in many schools that have ensured learning and teaching is effective among students. Apart from word processing, the internet is one of the excellent tools in modern technologies used by instructors and learners. Recently, the World Wide Web has become a frequently used tool in computer technologies in high schools and other organizations. More so, teachers benefit from using electronic mail to reach their students. Use of ICT in learning is not supposed to be considered as the only way of transferring better skills and rehearsals but means for knowledge acquisition, discovery, distributing as well as creating knowledge. The infrastructural issues are considered to be of greater importance compared to improving learning and teaching. Teachers are stakeholders in school and involved directly with the technology thus should be given a chance to contribute to decision-making.

Involving instructors in each process of implementation is an essential way of improving learning, and be guaranteed that the method is of significant advantages over other systems. In addition, teachers should realize that compatibility of their teaching practices and ICT require technical assistance and training. Consequently, in the integration of ICT in education transformations are anticipated to be executed in future regarding the methodology of teaching in schools. Stakeholders must be prepared for such changes and accept the implementation of new technologies (Blanchard et al., 2016). The approaches to training and knowledge acquisition matter a lot and tutors should be given support with teaching instruments together with models. Any course interlinked to learning technology in the education sector must be redesigned and to suit the current technological needs. More studies that specifically utilize 
qualitative methods can be done to validate and elaborate quantitative results. This study is essential and enlightens high school instructors and school administrators to initiate projects, which should be supported by the Ministry of Education to incorporate ICT into their academic program. Besides, the initiative of the use of modern innovation is anticipated to advance the level of teaching in several schools (Bingimlas, 2009).

\section{Recommendations}

The leadership of the schools applying any technology must ensure inclusion of everyone from the beginning to the end of programs. Administration in the school system must ensure proper planning for adoption of technology and find an appropriate model, for training as well as use. The hiring of full-time technology directors is recommended to provide the services required for any innovations to succeed in high schools. Instructors should alter their approach to teaching and handling learners while classrooms should adopt the student-centered learning techniques. Furthermore, teachers should be the primary facilitators during learning to ensure maximum utilization of tools. Students should be allowed to employ technology in their projects in the process of collection and analyzing data. The use of technology in the school benefit not only the institution but also the community as a whole since new inventions that help in developments are likely to be developed using technological expertise. Although technology does not significantly influence the attendance and performance of the at-risk students, it is a substantial boost to the acquisition of relevant skills.

\section{References}

Aaen, J., \& Dalsgaard, C. (2016). Student Facebook groups as a third space: Between social life and schoolwork. Learning, Media, and Technology, 41(1), 160-186. https://doi.org/10.1080/17439884.2015.1111241

Abboud, M., \& Rogalski, J. (2017). Real uses of ICT in classrooms: Tensions and disturbances in the mathematics teacher's activity. CERME, 10, 2334-2341.

Anderson, T. (2016). Theories for learning with emerging technologies. In G. Veletsianos (Ed.), Emergence and Innovation in Digital Learning: Foundations and Applications (pp. 35-50). Edmonton, AB: Athabasca University Press.

Asterhan, C. S., \& Rosenberg, H. (2015). The promise, reality and dilemmas of secondary school teacher-student interactions in Facebook: The teacher perspective. Computers \& Education, 85, 134-148. http://dx.doi.org/10.1016/j.compedu.2015.02.003

Beauvois, M. H. (1998). Write to speak: The effects of electronic communication on the oral achievement of fourth-semester French students. In J.A. Muyskens, ed., New Ways of Learning and Teaching: Focus on Technology and Foreign Language Education, pp. 93-116. Boston: Heinle \& Heinle.

Bingimlas, K. A. (2009). Barriers to the successful integration of ICT in teaching and learning environments: A review of the literature. Eurasia Journal of Mathematics, Science \& Technology Education, 5(3), 235-245.

Borokhovski, E. F., Bernard, R. M., Tamim, R. M., \& Schmid, R. F. (2016). Technology integration in postsecondary education: A summary of findings from a set of related meta-analyses. Journal of Computing in Higher Education, 13(4), 284-302. http://dx.doi.org/10.21702/rpj.2016.4.17

Blanchard, M. R., LePrevost, C. E., Tolin, A. D., \& Gutierrez, K. S. (2016). Investigating technology-enhanced teacher professional development in rural, high-poverty middle schools. Educational Researcher, 45(3), 207-220. https://doi.org/10.3102/0013189X16644602

Brown, J. P. (2015). Complexities of digital technology use and the teaching and learning of function. Computers \& Education, 87, 112-122. https://doi.org/10.1016/j.compedu.2015.03.022

Cavas, B., Cavas, P., Karaoglan, B., \& Kisla, T. (2009). A Study on science teachers' attitudes toward information and communications technologies in education. The Turkish Online Journal of Educational Technology TOJET, 8(2), 20-32.

Chang, H. Y., Wang, C. Y., Lee, M. H., Wu, H. K., Liang, J. C., Lee, S. W. Y., ... \& Wu, Y. T. (2015). A review of features of technology-supported learning environments based on participants' perceptions. Computers in Human Behavior, 53, 223-237. https://doi.org/10.1016/j.chb.2015.06.042 
Clotfelter, C. T., Ladd, H. F., \& Vigdor, J. L. (2010). Teacher credentials and student achievement in high school a cross-subject analysis with student fixed effects. Journal of Human Resources, 45(3), 655-681. https://doi.org/10.1353/jhr.2010.0023

Cuban, L., Kirkpatrick, H., \& Peck, C. (2001). High access and low use of technologies in high school classrooms: Explaining an apparent paradox. American Educational Research Journal, 38(4), 813-834. https://doi.org/10.3102/00028312038004813

Darling-Aduana, J., \& Heinrich, C. J. (2017). The role of teacher capacity and instructional practice in the integration of educational technology for emergent bilingual students. Retrieved from http://vu-my.s3.amazonaws.com/wp-content/uploads/sites/2135/2016/06/26132540/Teacher-Capacity-for-Emer gent-English-Students.pdf

De Vita, M., Verschaffel, L., \& Elen, J. (2018). The power of interactive whiteboards for secondary mathematics teaching: Two case studies. Journal of Educational Technology Systems, 47(1), 50-78. https://doi.org/10.1177/0047239518767112

Ginieis, M., Sánchez-Rebull, M. V., \& Campa-Planas, F. (2012). The academic journal literature on air transport: Analysis using a systematic literature review methodology. Journal of Air Transport Management, 19, 31-35. https://doi.org/10.1016/j.jairtraman.2011.12.005

Goos, M., Galbraith, P., Renshaw, P., \& Geiger, V. (2000). Reshaping teacher and student roles in technology-enriched classrooms. Mathematics Education Research Journal, 12(3), 303-320.

Goldin, C., \& Katz, L. F. (2018). The race between education and technology. In Inequality in the 21st Century (pp. 49-54). Routledge.

Hegedus, S. J., Dalton, S., \& Tapper, J. R. (2015). The impact of technology-enhanced curriculum on learning advanced algebra in US high school classrooms. Educational Technology Research and Development, 63(2), 203-228. http://dx.doi.org/10.1007/s11423-015-9371-z

Heitink, M., Voogt, J., Verplanken, L., van Braak, J., \& Fisser, P. (2016). Teachers' professional reasoning about their pedagogical use of technology. Computers \& Education, 101, 70-83. https://doi.org/10.1016/j.compedu.2016.05.009

Hinostroza, J. E., Ibieta, A. I., Claro, M., \& Labbé, C. (2016). Characterisation of teachers' use of computers and Internet inside and outside the classroom: The need to focus on the quality. Education and Information Technologies, 21(6), 1595-1610. http://dx.doi.org/10.1007/s10639-015-9404-6

Huizenga, J. C., Ten Dam, G. T. M., Voogt, J. M., \& Admiraal, W. F. (2017). Teacher perceptions of the value of game-based learning in secondary education. Computers \& Education, 110, 105-115. https://doi.org/10.1016/j.compedu.2017.03.008

Ibieta, A., Hinostroza, J. E., Labbé, C., \& Claro, M. (2017). The role of the Internet in teachers' professional practice: activities and factors associated with teacher use of ICT inside and outside the classroom. Technology, Pedagogy, and Education, 26(4), 425-438. https://doi.org/10.1080/1475939X.2017.1296489

Islam, M. S., \& Grönlund, Å. (2016). An international literature review of 1: 1 computing in schools. Journal of Educational Change, 17(2), 191-222. http://doi.org/10.1007/s10833-016-9271-y

Knezek, G., \& Christensen, R. (2002). Impact of new information technologies on teachers and students. In Networking the Learner (pp. 169-178). Springer, Boston, MA. https://doi.org/10.1007/978-0-387-35596-2_17

Kennewell, S., Tanner, H., Jones, S., \& Beauchamp, G. (2008). Analyzing the use of interactive technology to implement interactive teaching. Journal of computer assisted learning, 24(1), 61-73. https://doi.org/10.1111/j.1365-2729.2007.00244.x

Manca, S., \& Ranieri, M. (2017). Implications of social network sites for teaching and learning. Where we are and where we want to go. Education and Information Technologies, 22(2), 605-622. https://doi.org/10.1007/s10639-015-9429-x

Mulrow, C. D. (1994). Systematic reviews: rationale for systematic reviews. BMJ, 309(6954), $597-599$. https://doi.org/10.1136/bmj.309.6954.597

Muir-Herzig, R. G. (2004). Technology and its impact in the classroom. Computers \& Education, 42(2), $111-131$. https://doi.org/10.1016/S0360-1315(03)00067-8 
Pennings, H. J., van Tartwijk, J., Wubbels, T., Claessens, L. C., van der Want, A. C., \& Brekelmans, M. (2014). Real-time teacher-student interactions: A dynamic systems approach. Teaching and Teacher Education, 37, 183-193. https://doi.org/10.1016/j.tate.2013.07.016

Picciano, A. G. (2002). Beyond student perceptions: Issues of interaction, presence, and performance in an online course. Journal of Asynchronous learning networks, 6(1), 21-40.

Rosenberg, H., \& Asterhan, C. S. (2018). "WhatsApp, Teacher?"-Student perspectives on teacher-student WhatsApp interactions in secondary schools. Journal of Information Technology Education-Research, 17, 205-226. https://doi.org/10.28945/4081

Rueda, L., Benitez, J., \& Braojos, J. (2017). From traditional education technologies to student satisfaction in Management education: A theory of the role of social media applications. Information \& Management, 54(8), 1059-1071. https://doi.org/10.1016/j.im.2017.06.002

Sang, G., Valcke, M., Van Braak, J., \& Tondeur, J. (2010). Student teachers' thinking processes and ICT integration: Predictors of prospective teaching behaviors with educational technology. Computers \& Education, 54(1), 103-112. https://doi.org/10.1016/j.compedu.2009.07.010

Sharma, S. K., Joshi, A., \& Sharma, H. (2016). A multi-analytical approach to predict the Facebook usage in higher education. Computers in Human Behavior, 55, 340-353. https://doi.org/10.1016/j.chb.2015.09.020

Simon, W. E., \& Ngololo, E. N. (2015). Teachers' use and integration of ICT in the teaching of Life Science: A case of two urban high schools in Namibia. Journal for Educators, 2(1).

Singh, S. (2018). Role of Information and communication technology in Education. Scholarly Research Journal for Humanity Science \& English Language, 6(26). https://doi.org/10.21922/srjhsel.v6i26.11577

Smith, P. K., Mahdavi, J., Carvalho, M., Fisher, S., Russell, S., \& Tippett, N. (2008). Cyberbullying: Its nature and impact in secondary school pupils. Journal of Child Psychology and Psychiatry, 49(4), 376-385. https://doi.org/10.1111/j.1469-7610.2007.01846.x

Shernoff, D. J., Ruzek, E. A., \& Sinha, S. (2017). The influence of the high school classroom environment on learning as mediated by student engagement. School Psychology International, 38(2), 201-218. https://doi.org/10.1177/0143034316666413

Shute, V. J., \& Rahimi, S. (2017). Review of computer-based assessment for learning in elementary and secondary education. Journal of Computer Assisted Learning, 33(1), 1-19. https://doi.org/10.1111/jcal.12172

Stepp-Greany, J. (2002). Student perceptions on language learning in a technological environment: Implications for the new millennium. Retrieved from https://scholarspace.manoa.hawaii.edu/bitstream/10125/25148/1/06_01_steppgreany.pdf

Van den Beemt, A., \& Diepstraten, I. (2016). Teacher perspectives on ICT: A learning ecology approach. Computers \& Education, 92, 161-170. https://doi.org/10.1016/j.compedu.2015.10.017

Wenglinsky, H. (1998). Does it compute? The relationship between educational technology and student achievement in mathematics. Princeton, NJ: Educational Testing Service (ETS). Retrieved January 19, 2013 from Educational Testing Service (ETC) http://www.ets.org/Media/Research/pdf/PICTECHNOLOG.pdf

Yang, K. T., Wang, T. H., \& Chiu, M. H. (2015). Study the Effectiveness of Technology-Enhanced Interactive Teaching Environment on Student Learning of Junior High School Biology. Eurasia Journal of Mathematics, Science \& Technology Education, 11(2), 263-275. https://doi.org/10.12973/eurasia.2015.1327a

Yllmaz, R. (2017). Exploring the role of e-learning readiness on student satisfaction and motivation in the flipped classroom. Computers in Human Behavior, 70, 251-260. https://doi.org/10.1016/j.chb.2016.12.085

Zheng, B., \& Warschauer, M. (2015). Participation, interaction, and academic achievement in an online discussion environment. Computers \& Education, 84, 78-89. https://doi.org/10.1016/j.compedu.2015.01.008 